\title{
Bespreekbaar maken van gezonde leefstijl en het sociale netwerk bij multiprobleemgezinnen door sociaal werkers
}

\author{
Gera Nagelhout · Latifa Abidi · Cynthia Lodder · Hermijn Schutte · Hein de Vries
}

Published online: 2 July 2020

(C) The Author(s) 2020

\begin{abstract}
Samenvatting In dit onderzoek keken we naar factoren die het bespreekbaar maken van het belang van een gezonde leefstijl en het sociale netwerk door sociaal werkers bij cliënten uit multiprobleemgezinnen kunnen bevorderen of belemmeren. We voerden kwalitatieve interviews uit onder veertien sociaal werkers uit Apeldoorn. Bevorderende factoren waren vooral organisatorisch van aard. Sociaal werkers ontvingen in deze periode regelmatig reminders om het belang van een gezonde leefstijl en het sociale netwerk te bespreken (via e-mails, nieuwsbrieven en tijdens teambesprekingen), wat een belangrijke bevorderende factor bleek te zijn. Het sociale netwerk werd standaard al besproken door sociaal werkers, maar de leefstijl niet altijd. Het is voor sociaal werkers makkelijker om het belang van een gezonde leefstijl of het sociale netwerk te bespreken wanneer de cliënt hierover een hulpvraag heeft. Wanneer de cliënt duidelijk ongezond leeft of een leefstijlgerelateerde aandoening heeft, maakt dat het ook makkelijker om leefstijl te bespreken. Voor veel sociaal werkers werkte het belemmerend dat de leefstijl en het sociale netwerk geen prioriteit hebben boven urgentere problematiek. De meeste andere belemmerende factoren waren gerelateerd aan de cliënt, bijvoorbeeld dat de cliënt midden in een crisissituatie zit, zelf geen probleem ervaart,
\end{abstract}

G. Nagelhout $(\bowtie) \cdot$ L. Abidi $\cdot$ H. de Vries

Afdeling Gezondheidsbevordering, Universiteit Maastricht (CAPHRI), Maastricht, Nederland

gera.nagelhout@maastrichtuniversity.nl

G. Nagelhout

Onderzoeksinstituut IVO, Den Haag, Nederland

C. Lodder

Stimenz, Apeldoorn, Nederland

H. Schutte

Leger des Heils, Apeldoorn, Nederland weerstand heeft ten opzichte van de hulpverlening of dat de cliënt een verstandelijke beperking of ernstige psychiatrische problematiek heeft, of ernstig verslaafd is.

Trefwoorden gezonde leefstijl · sociaal netwerk · multiprobleemgezinnen · sociaal werk

\section{Discussing a healthy lifestyle and social network among multi-problem families by social workers}

Abstract In this study we examined barriers and facilitators for social workers to discuss a healthy lifestyle and social network among clients from multi-problem families. We conducted qualitative interviews among 14 social workers from Apeldoorn, the Netherlands. Facilitators were mainly organizational factors. Reminders for social workers were particularly important. Social workers received regular reminders to discuss a healthy lifestyle and social network during the study period (through e-mails, newsletters, and during team meetings) and this turned out to be an important facilitator. Discussing social network was part of the standard method of social workers, but discussing healthy living not always. When clients requested help with healthy living or social network, it was easier for social workers to discuss these topics. Another facilitator was when clients clearly live unhealthy or have a lifestyle related health condition. An often-mentioned barrier was that healthy living and social network does not have priority over more urgent problems. Most other barriers were related to the clients. For example, clients who are in the midst of a crisis situation, who do not experience a problem themselves, who are resistant towards the assistance provided or who have an intellectual disability, serious psychiatric problems, or a serious addiction problem. 
Keywords Healthy lifestyle $\cdot$ Social network $\cdot$ Multiproblem families $\cdot$ Social work

\section{Inleiding}

Multiprobleemgezinnen zijn gezinnen waarin meestal financiële problemen spelen en waarin daarnaast bijvoorbeeld gezinsleden zijn met psychische problematiek, of opvoedproblemen kunnen spelen en/of een of meer gezinsleden in aanraking komen met justitie [1]. Mensen die in hun gezin te maken hebben met multiproblematiek leven vaak ongezonder dan de rest van de bevolking. Ze bewegen minder, eten vaker ongezonde voeding en hebben een minder goede ervaren gezondheid [2]. Daarnaast is het sociale netwerk bij deze groep mensen vaak minder groot en ervaren ze meer eenzaamheid [1, 2]. Mensen die zich gezonder voelen kunnen ook beter met problemen omgaan, terwijl een goed sociaal netwerk bij bepaalde problemen als hulpbron kan worden ingezet. Bij mensen uit multiprobleemgezinnen is het dus belangrijk om een gezondere leefstijl en versterking van het sociale netwerk te stimuleren. Sociaal werkers die al met het gezin werken en het vertrouwen van het gezin gewonnen hebben, hebben mogelijk een ingang om het belang van een gezonde leefstijl en het sociale netwerk bespreekbaar te maken.

Sociaal werkers die hulp bieden aan multiprobleemgezinnen krijgen te maken met een grote verscheidenheid aan problematiek. De gezinnen die ze begeleiden hebben veelal een verleden met veel verschillende hulpverleningsinstanties en gezinsleden wantrouwen vaak de zoveelste nieuwe hulpverlener [1]. Wanneer er in eerste instantie al een sociaal werker met het gezin werkt, en wanneer deze de meest urgente problematiek heeft aangepakt en (daarmee) het vertrouwen van het gezin heeft gewonnen, zou deze andere belangrijke onderwerpen bespreekbaar kunnen maken. Twee belangrijke onderwerpen zijn het bevorderen van een gezonde leefstijl en het versterken van het sociale netwerk. Onder gezonde leefstijl verstaan we in dit artikel voldoende bewegen (in lijn met de Beweegrichtlijn van de Gezondheidsraad), gezond eten (in overeenstemming met de Schijf van Vijf van het Voedingscentrum), niet roken, niet te veel alcohol drinken (in lijn met de richtlijn Goede Voeding van de Gezondheidsraad) en voldoende ontspannen. Versterking van het sociale netwerk betekent in dit artikel dat het sociale netwerk wordt uitgebreid met positieve, helpende contacten (zoals familie, vrienden of buren), die kunnen zorgen voor praktische, sociale of emotionele steun, en dat negatieve sociale contacten worden verbroken.

Het feit dat een onderwerp belangrijk is, zorgt er niet automatisch voor dat sociaal werkers het tijdens hun gesprekken met cliënten aandacht geven. Voordat het bespreekbaar maken van het belang van een gezonde leefstijl en het sociale netwerk gestimuleerd kan worden, is inzicht nodig in factoren die het be- spreekbaar maken belemmeren en bevorderen. Eerdere onderzoeken hebben zich niet specifiek gericht op het bespreken van een gezonde leefstijl en het sociale netwerk door sociaal werkers bij cliënten uit multiprobleemgezinnen. Wel zijn er onderzoeken gedaan naar factoren die het bespreken van het belang van een gezonde leefstijl door zorgprofessionals belemmeren en bevorderen. Die onderzoeken laten zien dat een tekort aan tijd het meest genoemd wordt als belemmerende factor [3-8]. Daarnaast zijn er andere organisatorische, belemmerende factoren (zoals te weinig personeel, te weinig verwijsmogelijkheden en de aanwezigheid van andere zaken die een grotere prioriteit hebben) en bevorderende factoren (bijvoorbeeld het krijgen van scholing, steun van het management en vergoedingen) $[3,4,6,8-12]$. Verder zijn er factoren die samenhangen met de professionals zelf. Dan gaat het om bevorderende factoren als het belang van een gezonde leefstijl inzien, vinden dat het bespreken hiervan tot de functie van sociaal werkers behoort, zelf gemotiveerd zijn om gezond leven te bespreken en ook zelf gezond te leven, en om belemmerende factoren, zoals te weinig kennis of vaardigheden hebben, of een lage eigen effectiviteit hebben [3-5, 7-12]. En ten slotte spelen ook cliëntfactoren een rol: bevorderende factoren als het hebben van een leefstijlgerelateerde ziekte of aandoening en het vertrouwen dat de cliënt in de hulpverlener heeft, en belemmerende factoren, zoals een geringe bereidheid om naar advies te luisteren, of geen interesse in of het niet naleven van adviezen [4, 5, 10-12]. Onderzoek naar het bespreken van leefstijl heeft zich meer gericht op belemmerende factoren dan op bevorderende factoren $[4,6]$.

In dit onderzoek beantwoorden we de volgende onderzoeksvraag: welke factoren bevorderen of belemmeren sociaal werkers bij het bespreekbaar maken van het belang van een gezonde leefstijl en het sociale netwerk bij cliënten uit multiprobleemgezinnen? Voor zover wij weten is dit het eerste onderzoek naar dit onderwerp dat onder sociaal werkers is uitgevoerd.

\section{Methode}

We deden dit kwalitatieve onderzoek als onderdeel van een interventieonderzoek naar het bevorderen van een gezonde leefstijl en het verbeteren van het sociale netwerk van multiprobleemgezinnen in Apeldoorn [13]. Voor dit interventieonderzoek werden cliënten uit multiprobleemgezinnen geworven via hun sociaal werker. Daarna werd een leefstijlprogramma, genaamd Back2Balance, aangeboden aan deze cliënten. Een leefstijlprogramma is een interventie die mensen stimuleert om gezonder te gaan leven. Ons programma werd uitgevoerd door welzijnsorganisatie Stimenz en bestond uit een wekelijkse wandelgroep, maandelijks samen koken en eten, kinderactiviteiten die eenmaal per kwartaal werden georganiseerd (bijvoorbeeld trampolinespringen), ge- 
zellige uitjes, ook één keer per kwartaal (bijvoorbeeld bezoek aan de dierentuin) en kortingsmogelijkheden op het bestaande leefstijlaanbod in Apeldoorn (zoals de sportschool of het zwembad). De activiteiten werden begeleid door een activiteitenbegeleider van Stimenz, die tijdens de activiteiten verschillende onderwerpen besprak, zoals voldoende groente en fruit eten en de hoeveelheid suiker in frisdrank (tijdens het koken), en met de groep ontspanningsoefeningen deed (tijdens het wandelen). De activiteitenbegeleider had tussen de activiteiten door geregeld contact met de groep via WhatsApp en Facebook. Om het effect van het leefstijlprogramma te vergroten, werd aan sociaal werkers gevraagd om met de cliënt regelmatig te praten over het belang van een gezonde leefstijl (vooral voeding en beweging), het sociale netwerk en het leefstijlprogramma. De sociaal werkers kregen uitleg over deze nieuwe taak via een onderzoekstoelichting die ze digitaal en op papier ontvingen, via nieuwsbrieven, e-mails, speciaal georganiseerde bijeenkomsten over het onderzoek en in de vorm van updates tijdens teamvergaderingen van de sociaal werkers. Deelname aan de speciaal georganiseerde bijeenkomsten over het onderzoek was niet verplicht, maar teamleiders stimuleerden deze wel. Sociaal werkers werden vrijgelaten in de manier waarop en de mate waarin ze met hun cliënten over een gezonde leefstijl, het sociale netwerk en het leefstijlprogramma spraken.

We voerden kwalitatieve interviews uit onder sociaal werkers die cliënten hadden doorverwezen naar het interventieonderzoek. Twaalf interviews werden telefonisch afgenomen en twee interviews werden (op verzoek van de geïnterviewden) per e-mail afgenomen. De meeste geïnterviewden waren werkzaam bij een sociaal wijkteam of een organisatie voor gezinsondersteuning (zie tab. 1). Eén geïnterviewde was praktijkondersteuner in een huisartsenpraktijk, maar we noemen de geïnterviewden in dit artikel voor het gemak allemaal 'sociaal werkers'.

Tabel 1 Kenmerken van de geïnterviewde sociaal werkers $(n=14)$

\begin{tabular}{|l|c|}
\hline Geslacht & $n(\%)$ \\
\hline - Vrouw & $10(70 \%)$ \\
\hline - Man & $4(30 \%)$ \\
\hline Werksituatie & \\
\hline - In loondienst & $11(80 \%)$ \\
\hline - Zelfstandig & $3(20 \%)$ \\
\hline Organisatie & \\
\hline - Sociaal Wijkteam & $5(45 \%)$ \\
\hline - Passie voor Jeugd \& Gezin & $3(27 \%)$ \\
\hline - Stimenz & $1(9 \%)$ \\
\hline - Leger des Heils & $1(9 \%)$ \\
\hline - Huisartsenpraktijk & $1(9 \%)$ \\
\hline
\end{tabular}

De semigestructureerde interviews behandelden factoren die het bespreken van een gezonde leefstijl, het sociale netwerk en het leefstijlprogramma bevorderen en belemmeren (zie box 1). Twee auteurs (LA en CL) namen de interviews tussen januari en april 2018 af. LA is getraind en ervaren in het afnemen van kwalitatieve interviews. LA en CL hebben voor de start van de interviews samen de topiclijst doorgenomen en LA heeft CL tips en instructies gegeven over het interviewen. Daarna hebben ze de interviews afzonderlijk van elkaar afgenomen. De interviews duurden gemiddeld 7 minuten.

Alle telefonische interviews werden opgenomen en getranscribeerd. De transcripten van de telefonische interviews en de twee e-mailinterviews werden thematisch geanalyseerd door GN en LA. GN las eerst alle transcripten door en maakte vervolgens op inductieve wijze een lijst met codes, waarbij onderscheid werd gemaakt tussen bevorderende en belemmerende factoren. Daarna codeerden GN en LA onafhankelijk van elkaar de veertien interviews. Niet-overeenkomende coderingen werden besproken om tot consensus te komen. Ten slotte werden de codes onder bevorderende en belemmerende factoren onderverdeeld in organisatorisch, professional en cliëntgerelateerd.

\section{Resultaten}

\section{Bevorderende factoren: organisatorisch}

De meeste bevorderende factoren die sociaal werkers in de interviews noemden waren organisatorisch van aard (zie tab. 2). Vooral herinneringen bleken belangrijk. De meeste hulpverleners (8/14) gaven aan dat ze geregeld werden herinnerd aan het bespreken van een gezonde leefstijl en het sociale netwerk door informatie en reclame vanuit het leefstijlprogramma (e-mails, nieuwsbrieven, posters, flyers en updates in teamvergaderingen van sociaal werkers) en dat dit bevorderend werkte. 'Wat heeft geholpen is dat we natuurlijk uitgebreide informatie gehad hebben op papier. Mail erover gehad, een bijeenkomst erover gehad, dat er hier iemand wat kwam vertellen in het team' (hulpverlener \#1).

Hoewel er vanuit het programma veel werd geïnvesteerd in reminders via e-mails, nieuwsbrieven, posters, flyers en meerdere updates in teamvergaderingen van de sociaal werkers, was dat niet voor iedereen voldoende. 'Ik denk eigenlijk dat de projectmedewerkers niet zo'n heel makkelijke taak hebben, omdat wij als maatschappelijk werkers zo generalistisch werken worden we gevraagd voor een heleboel dingen en zij staan dan "in de rij”. (...) Misschien zouden ze nog eens een keer in een teamvergadering kunnen aansluiten om over hun project te vertellen, een update te geven' (hulpverlener \#1).

Ook het feit dat het bespreken van het sociale netwerk een standaardonderdeel is van de hulpverlening werd vaak genoemd (7/14). Sociaal werkers gaven aan 
Tabel 2 Samenvatting van de belangrijkste resultaten

\begin{tabular}{|c|c|c|}
\hline & Bevorderende factoren & Belemmerende factoren \\
\hline \multirow[t]{4}{*}{ Organisatorisch } & $\begin{array}{l}\text { Reminders over het bespreken van de leefstijl } \\
\text { en het sociale netwerk (8/14) }\end{array}$ & Gebrek aan tijd (4/14) \\
\hline & $\begin{array}{l}\text { Bespreken van het sociale netwerk is stan- } \\
\text { daardonderdeel van hulpverlening }(7 / 14)\end{array}$ & \\
\hline & $\begin{array}{l}\text { Bespreken van de leefstijl is standaardonder- } \\
\text { deel van hulpverlening (4/14) }\end{array}$ & \\
\hline & $\begin{array}{l}\text { Bespreken omdat de cliënt meedoet aan het } \\
\text { leefstijlprogramma (5/14) }\end{array}$ & \\
\hline \multirow[t]{3}{*}{ Professional } & $\begin{array}{l}\text { Bespreken van de leefstijl is geen probleem of } \\
\text { makkelijk (5/14) }\end{array}$ & $\begin{array}{l}\text { Urgentere problematiek heeft prioriteit boven ge- } \\
\text { zonde leefstijl en het sociale netwerk (6/14) }\end{array}$ \\
\hline & $\begin{array}{l}\text { Bespreken van het sociale netwerk is geen } \\
\text { probleem of makkelijk (4/14) }\end{array}$ & $\begin{array}{l}\text { Gebrek aan kennis over het leefstijlpro- } \\
\text { gramma }(3 / 14)\end{array}$ \\
\hline & $\begin{array}{l}\text { Kennis hebben over verwijsmogelijkheden } \\
\text { naar 'ontmoetingsplekken' (4/14) }\end{array}$ & \\
\hline \multirow[t]{6}{*}{ Cliënt } & $\begin{array}{l}\text { Cliënt heeft zelf een hulpvraag over gezonde } \\
\text { leefstijl of het sociale netwerk (8/14) }\end{array}$ & Cliënt zit midden in een crisissituatie (7/14) \\
\hline & $\begin{array}{l}\text { Cliënt leeft duidelijk ongezond of heeft een } \\
\text { leefstijlgerelateerde aandoening (7/14) }\end{array}$ & $\begin{array}{l}\text { Cliënt ervaart zelf geen probleem of heeft weer- } \\
\text { stand ( } 7 / 14)\end{array}$ \\
\hline & $\begin{array}{l}\text { Cliënt zit in een stabielere situatie en meest } \\
\text { urgente problematiek is aangepakt (3/14) }\end{array}$ & $\begin{array}{l}\text { Cliënt heeft een verstandelijke beperking of psychia- } \\
\text { trische problematiek, of is verslaafd (7/14) }\end{array}$ \\
\hline & & Cliënt is heel wantrouwig (4/14) \\
\hline & & Cliënt heeft weinig geld (5/14) \\
\hline & & Cliënt heeft weinig tijd of mentale ruimte (4/14) \\
\hline
\end{tabular}

dat het onderdeel was van de intake, het gezinsplan, de leefgebieden die ze moeten behandelen of van een stroomschema waar ze gebruik van maken. 'Dat zit in ons proces. We hebben eens soort van stroomschema en daarin staat ook een netwerkanalyse en het is ook een onderwerp van het gezinsplan. Dit plan is van de cliënt en daar wordt ook het netwerk bij betrokken. Dat doen we in ieder geval' (hulpverlener \#6).

Minder sociaal werkers gaven aan dat het spreken over gezonde leefstijl een standaardonderdeel was van de hulpverlening (4/14). Sommige sociaal werkers gaven expliciet aan dat gezonde leefstijl geen standaardonderdeel is van de hulpverlening, terwijl dit wel geldt voor het sociale netwerk.

Ten slotte gaf een aantal sociaal werkers (5/14) aan dat ze vroegen naar de leefstijl en het sociale netwerk omdat de cliënt meedeed aan het leefstijlprogramma. 'Tja, dat komt eigenlijk zeg maar door Back2Balance. Hierdoor werd het een onderwerp' (hulpverlener \#10).

\section{Bevorderende factoren: professional}

Een bevorderende factor gerelateerd aan de professional was dat de sociaal werkers het bespreken van de leefstijl geen probleem of makkelijk vonden (5/14). Dit wil niet zeggen dat ze het makkelijk vonden om de leefstijl van de cliënt daadwerkelijk te veranderen, maar wel om deze te bespreken. 'Nou moeilijk in de zin van uhm, om mensen zo ver te krijgen is soms moeilijk. Maar een onderwerp bespreken is niet zo moeilijk. In principe bespreek ik alles met mijn cliënten en ik denk dat dat ook voor mijn collega's geldt' (hulpverlener \#2). Hetzelfde werd gezegd over het bespreken van het sociale netwerk van de cliënt (4/14).

Een andere bevorderende factor die door enkele sociaal werkers werd genoemd is dat ze kennis hebben van verwijsmogelijkheden naar zogenaamde 'ontmoetingsplekken' in Apeldoorn (4/14). 'Op het moment dat er tijd en ruimte bij de klant is maak ik het zeker bespreekbaar. Of probeer ik te verwijzen naar de ontmoetingsplekken en dat soort dingen' (hulpverlener \#4).

\section{Bevorderende factoren: cliënt}

Een veelgenoemde bevorderende factor gerelateerd aan de cliënt $(8 / 14)$ betrof gevallen waarin de cliënt zelf een hulpvraag heeft over gezond leven of het sociale netwerk. Het werkte ook bevorderend als de cliënt duidelijk ongezond leeft of een leefstijlgerelateerde aandoening heeft $(7 / 14)$. 'Als ik zie dat ze ongezond leven, dan moet dat er heel dik bovenop liggen of het moet een link hebben met de hulpvraag of de klachten. Dan komt het zeker aan bod' (hulpverlener \#2).

Een enkeling (3/14) zei het makkelijker te vinden om de leefstijl en het sociale netwerk te bespreken als de cliënt zich in een stabielere situatie bevindt en de meest urgente problematiek is aangepakt. 'Daar was ik al een tijdje bij geweest en dat was redelijk stabiel. En dan merk je wel als er dingen op orde zijn dat je hier dan ook aandacht aan kan geven. Ja, als alles een beetje opgelost is, zoals ze hebben een eigen woning, dat zit goed. Dan kom je meestal toe aan dit soort aspecten' (hulpverlener \#3). 


\section{Belemmerende factoren: organisatorisch}

Er werd in de interviews met sociaal werkers slechts één organisatorische belemmering genoemd, namelijk een gebrek aan tijd (4/14). 'Ja tijd, tijd ... Het was soms zo, ik heb dan 2 uur in de week voor deze mevrouw, maar er kwamen ook allerlei andere problemen bij. Met haar dochter. Dan moest ik soms mee met gesprekken op school. (...) Afspraken kunnen naar andere doeleinden gaan dan wat eigenlijk de bedoeling was' (hulpverlener \#11).

\section{Belemmerende factoren: professional}

Hoewel een gebrek aan tijd slechts door vier sociaal werkers werd benoemd, zeiden meer sociaal werkers dat de leefstijl en het sociale netwerk minder prioriteit hebben dan urgentere problematiek (6/14). 'Op dit moment zit hij behoorlijk in de rats. Er is weinig te motiveren op dit moment. Hij komt waarschijnlijk op straat te staan, dus daar zijn we meer mee bezig als met Back2Balance, zeg maar' (hulpverlener \#8).

Hoewel dit ook gezien kan worden als belemmerende factor op het niveau van de cliënt, is het de sociaal werker die in deze gevallen aangeeft dat het bespreken van leefstijl en het sociale netwerk in deze situaties geen prioriteit heeft.

Ook vertelde een enkeling (3/14) dat een gebrek aan kennis over het leefstijlprogramma een belemmering vormde. 'Ik dacht als ze nou eerst eens meedoen aan het onderzoek, dan gaat mijn collega van Back2Balance hen wel enthousiasmeren. Die kan waarschijnlijk ook meer vertellen over wat voor activiteiten er precies zijn. Want mensen willen dan toch graag weten van wat is het nou precies? En waar? En hoe vaak? En dan moet ik het antwoord daarop schuldig blijven' (hulpverlener \#1).

\section{Belemmerende factoren: cliënt}

De meeste belemmerende factoren die sociaal werkers noemden waren gerelateerd aan de cliënt (zie tab. 2). Wanneer de cliënt zich midden in een crisissituatie bevond, werd dat vaak als belemmerende factor genoemd (7/14). 'Wanneer er zoveel speelt in het gezin en er bijna geen ruimte is om hierbij stil te staan. (...) Als er problemen op diverse gebieden ontstaan willen ouders toch vaak eerst rust voordat ze verder kunnen bouwen' (hulpverlener \#7).

Hoewel sommigen ook wel aangaven dat ze op zo'n moment er wel even over beginnen en er later (wanneer de meest urgente problemen zijn aangepakt) uitgebreider op terugkomen. 'Ik benoem het direct al. Als iemand geen inkomen heeft en ik bezig ben om de voedselbank in te zetten: beetje goed voor jezelf zorgen. En kom ik er later op terug. Ik maak het al wel bespreekbaar en ik zaai al een klein zaadje zeg maar bij de ander. Later ga ik daarop uitbouwen' (hulpverlener \#4).
Vaak vormde ook het feit dat de cliënt zelf geen probleem ervaart of weerstand heeft ten opzichte van de hulpverlening een belemmerende factor (7/14), of wanneer de cliënt een verstandelijke beperking, ernstige psychiatrische problematiek of een ernstige verslaving heeft $(7 / 14)$, of in sommige gevallen waarin de cliënt heel wantrouwig is $(4 / 14)$. 'Bij één cliënt is dat wel een problematisch ding, dat is ook iemand met psychiatrische klachten. Die wil wel, maar zegt dat het niet nodig is. Het is een wat lastig persoon in de omgang' (hulpverlener \#1).

Ook een gebrek aan geld bij de cliënt werd als belemmerende factor gezien (5/14). 'Ik had vrijdag bijvoorbeeld nog een overleg met iemand die zegt: "Ik kan helemaal niet gezond eten, want ik heb helemaal geen geld om boodschappen te doen." Dus geld is ook vaak wel een probleem' (hulpverlener \#3).

Ook gaven sommige sociaal werkers aan dat de cliënt weinig tijd of mentale ruimte heeft (4/14). 'Ja, zijn draaglast, heb ik het idee. Hij kan ook niet heel veel aan. Hij werkt dan de hele week en dat kost hem veel energie. Hij vindt het dan lastig om iets te doen buiten zijn normale programma om' (hulpverlener \#5).

\section{Beschouwing}

Factoren die het door sociaal werkers bespreekbaar maken van de leefstijl en het sociale netwerk bij cliënten uit multiprobleemgezinnen bevorderden waren veelal organisatorisch van aard. Vooral herinneringen bleken voor sociaal werkers belangrijk. Op basis van de resultaten van ons onderzoek kunnen we dan ook aanbevelen om reminders op te nemen die sociaal werkers er geregeld aan herinneren om belangrijke onderwerpen bespreekbaar te maken. Dit wordt al gedaan voor het bespreken van het sociale netwerk en kan nog verbeterd worden voor gezonde leefstijl, bijvoorbeeld door reminders op te nemen als standaardonderdeel van de intake, het gezinsplan, de leefgebieden die sociaal werkers moeten behandelen of een stroomschema waar ze gebruik van maken. Ook bij leefstijlprogramma's waarbij sociaal werkers een rol spelen raden we aan om gebruik te maken van reminders, bijvoorbeeld door het versturen van e-mails en nieuwsbrieven, ophangen van posters, uitdelen van flyers en het regelmatig geven van updates tijdens teamvergaderingen. Eerdere onderzoeken bevestigen dat reminders een positief effect kunnen hebben op het veranderen van het gedrag van professionals [14-16]. Toekomstig onderzoek zou kunnen kijken welk type reminders het beste werkt.

Ten opzicht van de eerder besproken literatuur over het bespreken van de leefstijl door zorgverleners [3-12] noemden sociaal werkers tijd minder vaak als belemmerende factor en ging het hen vaker om prioriteiten en niet alleen tijd. Cliënten met multiproblematiek hebben geregeld heel hoge schulden, of er zijn zorgen over de veiligheid van de kinderen of een 


\section{Box 1. Topiclijst}

Hebt $u$ een gesprek gehad met uw cliënt over leefstijl? Zo ja, in hoeverre hebt u uw cliënt gestimuleerd om zijn/haar leefstijl te veranderen? Op welke manier hebt $\mathrm{u}$ dit gedaan?

Waren er bevorderende factoren die ervoor zorgden dat $\mathrm{u}$ het gesprek over leefstijlverandering bent aangegaan met uw cliënt? Waren er ook belemmerende factoren die het lastig voor u maakten om uw cliënt te stimuleren om zijn/haar leefstijl te veranderen?

Indien u geen gesprek hebt gehad met uw cliënt over leefstijlverandering, waarom heeft het gesprek niet plaatsgevonden?

Hebt u een gesprek gehad met uw cliënt over netwerkversterking? Zo ja, in hoeverre hebt u uw cliënt gestimuleerd om zijn/haar netwerk te vergroten/te versterken? Op welke manier hebt $\mathrm{u}$ dit gedaan?

Waren er bevorderende factoren die ervoor zorgden dat $\mathrm{u}$ het gesprek bent aangegaan met uw cliënt over netwerkversterking? Waren er ook belemmerende factoren die het lastig voor u maakten om uw cliënt te stimuleren om zijn/haar netwerk te versterken?

Indien u geen gesprek hebt gehad met uw cliënt over netwerkversterking, waarom heeft het gesprek niet plaatsgevonden?

Hebt $\mathrm{u}$ een gesprek gehad met uw cliënt over het Back2Balance-programma? Zo ja, in hoeverre hebt $\mathrm{u}$ uw cliënt gestimuleerd om aan het Back2Balance-programma mee te doen? Op welke manier hebt u dit gedaan?

Waren er bevorderende factoren die ervoor zorgden dat $\mathrm{u}$ het gesprek bent aangegaan met uw cliënt? Waren er ook belemmerende factoren die het lastig voor u maakten om uw cliënt te stimuleren om aan Back2Balance mee te doen?

Indien u geen gesprek hebt gehad met uw cliënt over Back2Balance-programma, waarom heeft het gesprek niet plaatsgevonden?

Hebt u tips of verbeterpunten voor het Back2Balance-programma?

dreigende uithuisplaatsing. Het oplossen van deze problemen is uiteraard ook voor een sociaal werker urgenter dan het bevorderen van gezond leven en het verbeteren van het sociale netwerk [17]. Toch kunnen cliënten zich prettiger gaan voelen door een gezondere leefstijl en een beter sociaal netwerk. Zelfs heel kleine veranderingen, zoals regelmatig een paar minuten wandelen, kunnen al veel voor de (mentale en fysieke) gezondheid en het welzijn betekenen, waardoor de betrokkene ook weer beter met problemen kan omgaan en de hulpverlening wellicht effectiever kan worden. Daarom is het ook belangrijk dat sociaal werkers de tijd vinden om deze onderwerpen te bespreken.
Een gebrek aan scholing, kennis en vaardigheden werden in ons onderzoek - anders dan in andere onderzoeken - door sociaal werkers niet als belemmeringen genoemd. Sociaal werkers gaven juist als bevorderende factor aan dat ze het bespreken van de leefstijl en het sociale netwerk geen probleem of makkelijk vonden. Weliswaar gold dit niet voor de meerderheid, maar het gaat vermoedelijk ook op voor andere respondenten die dit niet uit zichzelf hebben benoemd. In ieder geval noemde niemand het bespreken van de leefstijl of het sociale netwerk moeilijk en was dat dus ook geen belemmerende factor. We kunnen hieruit voorzichtig concluderen dat er weinig handelingsverlegenheid is bij deze onderwerpen. Extra scholing kan mogelijk wel helpen om de leefstijl en het sociale netwerk vaker en effectiever bespreekbaar te maken, of om cliënten met een problematischere casus te bereiken, zoals cliënten met een verstandelijke beperking. Leefstijlbegeleiding die ook daadwerkelijk tot gedragsverandering bij een cliënt leidt is niet makkelijk en we mogen er dan ook niet vanuit gaan dat sociaal werkers dit goed kunnen omdat ze zelf aangeven dat ze het makkelijk vinden.

Ons onderzoek is, voor zover wij weten, het eerste onderzoek naar factoren die het door sociaal werkers bij cliënten uit multiprobleemgezinnen bespreekbaar maken van de leefstijl en het sociale netwerk bevorderen of belemmeren. Eerdere onderzoeken naar vergelijkbare onderwerpen, maar met andere doelgroepen, keken vaker naar belemmerende dan naar bevorderende factoren. Juist onze resultaten met betrekking tot bevorderende factoren geven belangrijke aanknopingspunten voor verbetering van de praktijk.

Dit onderzoek had echter ook beperkingen. We hebben slechts veertien sociaal werkers geïnterviewd, van wie twee per e-mail in plaats van telefonisch. Ook waren de interviews kort en bleven de antwoorden beperkt. Verder doorvragen naar onderliggende redenen was lastig omdat de deelnemende sociaal werkers niet veel tijd vrij konden maken voor het onderzoek. Verder is het aannemelijk dat vooral meer gemotiveerde sociaal werkers aan dit onderzoek hebben meegedaan. Daarnaast weten we niet of onze resultaten gegeneraliseerd kunnen worden naar sociaal werkers in andere regio's dan de regio Apeldoorn. Ten slotte zou het goed zijn geweest om een kwantitatieve voormeting en nameting te doen van het bespreken van de leefstijl en het sociale netwerk. Zo hadden we kunnen vaststellen of sociaal werkers deze onderwerpen vaker zijn gaan bespreken. Helaas hebben we dergelijke gegevens niet verzameld en leverden de interviews ook onvoldoende informatie op om daarover een uitspraak te kunnen doen.

\section{Conclusie}

Het bespreken van de leefstijl en het sociale netwerk bij cliënten uit multiprobleemgezinnen heeft voor sociaal werkers geen prioriteit boven het aanpakken van 
urgentere problematiek. Toch worden deze onderwerpen wel besproken als ze onderdeel uitmaken van de standaardwerkwijze van de hulpverlening en opgenomen zijn in een intakeformulier of gezinsplan. Ook bij cliënten die duidelijk ongezond leven of een leefstijlgerelateerde aandoening hebben, bespreken sociaal werkers het onderwerp. Sociaal werkers zeggen er geen moeite mee te hebben om deze onderwerpen bespreekbaar te maken, behalve bij cliënten die bijvoorbeeld een verstandelijke beperking of ernstige psychiatrische problematiek hebben, of verslaafd zijn.

Dankbetuiging Dit onderzoek werd gefinancierd door het FNO-programma Gezonde Toekomst Dichterbij. We danken de sociaal werkers die hebben meegewerkt aan ons onderzoek. Onze dank gaat ook uit naar het Back2Balance-projectteam: Natalie Spaans, Tamar Jansen, Renate Spruijt, Nathalie Postma, Hermien Marsman, Babette Tempelman, Jannie Jonker, Karin Gasseling en Weslie Gerrits.

Open Access This article is licensed under a Creative Commons Attribution 4.0 International License, which permits use, sharing, adaptation, distribution and reproduction in any medium or format, as long as you give appropriate credit to the original author(s) and the source, provide a link to the Creative Commons licence, and indicate if changes were made. The images or other third party material in this article are included in the article's Creative Commons licence, unless indicated otherwise in a credit line to the material. If material is not included in the article's Creative Commons licence and your intended use is not permitted by statutory regulation or exceeds the permitted use, you will need to obtain permission directly from the copyright holder. To view a copy of this licence, visit http://creativecommons.org/licenses/by/4.0/.

\section{Literatuur}

1. Steketee M, Jansma A, Gilsing R. Wat werkt bij multiprobleemgezinnen? Ervaringen uit Rotterdam. Utrecht: Verwey-Jonker Instituut; 2015.

2. Nagelhout GE, Abidi L, Vries H de. How do health and social networks compare between low-income multiproblem households and the general population? Int J Environ Res Public Health. 2019;16(24):4967.

3. Naylor P-J, Nettlefold L, Race D, Hoy C, Ashe MC, Higgins JW, et al. Implementation of school based physical activity interventions: a systematic review. Prev Med. 2015;72:95-115.

4. Hébert ET, Caughy MO, Shuval K. Primary care providers' perceptions of physical activity counselling in a clinical setting: a systematic review. Br J Sports Med. 2012;46(9):625-31.

5. Rubio-Valera M, Pons-Vigués M, Martínez-Andrés M, Moreno-Peral $\mathrm{P}$, Berenguera A, Fernández A. Barriers and facilitators for the implementation of primary prevention and health promotion activities in primary care: a synthesis through meta-ethnography. Plos One. 2014;9(2):e89554.

6. Green S, James E. Barriers and facilitators to undertaking nutritionalscreening of patients: asystematicreview. JHum Nutr Diet. 2013;26(3):211-21.

7. Gravel K, Légaré F, Graham ID. Barriers and facilitators to implementing shared decision-making in clinical practice: a systematic review of health professionals' perceptions. Implement Sci. 2006;1(1):16.

8. LaatSde, Jacobs M, MarkusA, MilEvan, Goor Lvande. Derol van de jeugdverpleegkundige en jeugdarts in de ketenaanpak voor kinderen met overgewicht in 's-Hertogenbosch. JGZTijdschr Jeugdgezondheidsz. 2019;51(6):161-7.

9. Dera-de Bie E, Jansen M, Gerver W. Belemmerende factoren in de preventie van overgewicht bij jonge kinderen: een exploratief kwalitatief onderzoek bij jeugdgezondheidszorgprofessionals. JGZ Tijdschr Jeugdgezondheidsz. 2012;44(6):105-12.

10. Arora A, Poudel P, Manohar N, Bhole S, Baur LA. The role of oral health care professionals in preventing and managing obesity: a systematic review of current practices and perceived barriers. Obes Res Clin Pract. 2019;13:217-25.

11. Johnson M, Jackson R, Guillaume L, Meier P, Goyder E. Barriers and facilitators to implementing screening and briefintervention for alcohol misuse: a systematic review of qualitative evidence. JPublic Health. 2010;33(3):412-21.

12. Wändell PE, Waard A-KM de, Holzmann MJ, Gornitzki C, Lionis $\mathrm{C}$, Wit $\mathrm{N}$ de, et al. Barriers and facilitators among health professionals in primary care to prevention of cardiometabolic diseases: a systematic review. Fam Pract. 2018;35(4):383-98.

13. Abidi L, Nagelhout G, Spruijt R, Schutte H, Vries H de. A quasi-experimental study evaluating a health promotion program targeting healthy nutrition, physical activity and social network enhancement for low-income multiproblem households: study protocol. Int J Clin Trials. 2018;5(3):132-41.

14. Cheung A, Weir M, Mayhew A, Kozloff N, Brown K, Grimshaw J. Overview of systematic reviews of the effectiveness of reminders in improving healthcare professional behavior. Syst Rev. 2012;1(1):36.

15. Jeppesen C, Kristensen JK, Ovesen P, Maindal HT. The forgotten risk? A systematic review of the effect of reminder systems for postpartum screening for type 2 diabetes in women with previous gestational diabetes. BMC Res Notes. 2015;8(1):373.

16. Pantoja T, Grimshaw JM, Colomer N, Castañon C, Leniz Martelli J. Manually-generated reminders delivered on paper: effects on professional practice and patient outcomes. CochraneDatabase Syst Rev. 2019;12:CD1174.

17. Nagelhout GE, Abidi L, Jansen T. Leefstijlverandering en netwerkversterking bij multiproblematiek. Stimuleren is een aparte taak voor het sociaal werk. Vakbl Soc Werk. 2019;20:27-9. 